\title{
Belief reinforcement: one reason why costs for low back pain have not decreased
}

\author{
This article was published in the following Dove Press journal: \\ Journal of Multidisciplinary Healthcare \\ 15 May 2013 \\ Number of times this article has been viewed
}

\author{
Max Zusman \\ Curtin University, School \\ of Physiotherapy, Faculty \\ of Health Science, Perth, \\ WA, Australia
}

Correspondence: Max Zusman

Curtin University, School of Physiotherapy, Faculty of Health Science, GPO Box 1987, Perth, Western Australia 6845, Australia $\mathrm{Tel}+6 \mathrm{I} 892664644$ Fax +6I 892663699

Emailm.zusman@curtin.edu.au

\begin{abstract}
Recent figures show that there has been no change in the upward trend of direct and indirect costs for the largely benign symptom of low back pain in Western societies. This is despite greater understanding and the recommendation of a much more conservative and independent approach to its management. Moreover, in recent years, several large-scale education programs that aim to bring knowledge of the public (including general practitioners) more in line with evidence-based best practice were carried out in different countries. The hope was that the information imparted would change beliefs, ie, dysfunctional patient behavior and biomedical practice on the part of clinicians. However, these programs had no influence on behavior or costs in three out of the four countries in which they were implemented. It is argued that one reason for the overall lack of success is that it is extremely difficult to alter the potentially disabling belief among the lay public that low back pain has a structural mechanical cause. An important reason for this is that this belief continues to be regularly reinforced by the conditions of care of a range of "hands-on" providers, for whom idiosyncratic variations of that view are fundamental to their professional existence.
\end{abstract}

Keywords: low back pain, loss of productivity, patients, providers, beliefs, manipulation, best practice

\section{Introduction}

Hardly a week passes without encountering somewhere in the literature an article quoting detailed information on what has become a major health care burden to Western industrialized societies, ie, low back pain. It is of paramount significance that most of the source reviews come to a similar conclusion. Namely, that over the past 25 or so years (since we first became "enlightened"), ${ }^{1}$ incidence and prevalence rates have remained relatively constant, while costs, particularly in terms of lost productivity, are outrageous and rising. ${ }^{2}$ During this period, several widespread evidence-based programs aimed at educating the lay public have been carried out. ${ }^{3}$ Early results for the concerted and expensive campaign conducted in Victoria, Australia, looked encouraging. ${ }^{4}$ However, those for Norway, Scotland, and Canada, while appearing to change beliefs, had no impact whatsoever on variables such as health care use, disability behaviors, and time off work. ${ }^{4}$

Specifically, there appears to be an $80 \%$ lifetime and $12 \%$ point prevalence, with only around $8 \%$ of (chronic) cases accounting for some $50 \%$ of the total cost. 5 Detailed costs vary from study to study and between countries, but in larger societies such as the US, for example, run into tens of billions of dollars annually. ${ }^{2}$ If motor vehicle accident is removed from the list, low back pain ranks as the fifth costliest 
of all health care conditions in that country (after ischemic heart disease, acute respiratory infection, the arthropathies, and hypertension). ${ }^{6}$ It is important to make the point that, while health care costs for low back pain are substantial, they are estimated to account for some $15 \%$ of the total only. The largest component by far is the so-called indirect costs, loosely termed "loss of productivity", which are responsible for the remaining $85 \%{ }^{7,8}$

More effective management, along with decreased costs, should have been especially the case with low back pain. Extensive evidence has demonstrated that, contrary to the long-held mechanical view, the overwhelming majority of cases had no "red flag" basis whatsoever (ie, so-called nonspecific LBP). ${ }^{9}$ Hence, unique among the aforementioned health care conditions, in the majority of instances, the natural history should be benign, management conservative, results generally satisfactory, and cost now well contained. Why then has such an evidence-based clinical best practice approach had so little worthwhile influence on the latest figures? Despite the revolution in understanding of low back pain, as mentioned above, the incidence, prevalence, disability, and in particular cost percentages appear essentially unchanged or increased.

Thus, education programs notwithstanding, the trend internationally has not altered, even in countries where these have been carried out. ${ }^{4}$ Gross et $\mathrm{al}^{4}$ suggest a number of possible factors contributing to this outcome. The following offers a further explanation, the roots which lie not with the in-pain, uninformed/misinformed, disabled, fearful (re activity), anxious (re the prognosis), trusting, and hopeful lay public, but within the reinforcement of erroneous, disabling, costly beliefs and behavior by the conditions of care of health care professionals from whom patients frequently seek treatment. ${ }^{10,11}$

\section{The SAB model}

The medical profession previously viewed low back pain as being the result of tissue pathology involving structural, anatomical, and biomechanical factors (SAB model). Hence it was commonly treated surgically or with often lengthy deconditioning pain-dictated bed rest. Alternative providers, including a subspecialty of the physiotherapy profession, also embraced the SAB model, but favored noninvasive fault correction, and were more concerned with structurally flawed passive (and active) movement than with either pain mechanisms or pathology. ${ }^{12-15}$

However, because the SAB model was too easily misinterpreted, the legacy has been one of unacceptable failure rates, iatrogenic mishaps, and a blowout in costs. ${ }^{2,16}$ Eventually this demanded a rethink ${ }^{1}$ which more or less coincided with game-changing increases in insight into the mechanisms of pain itself. ${ }^{17}$ Together, this contributed to evolution of the biopsychosocial model of pain. ${ }^{18,19}$ Recommended clinical best practice guidelines for diagnosis and treatment of low back pain appeared worldwide. ${ }^{20}$ For a majority of cases, these guidelines generally favored limited total rest and graduated resumption of everyday activities in spite of minor pain. Invasive treatment should be highly selective and even conservative treatment held to a minimum (in some instances, advice alone was deemed to be sufficient). ${ }^{21}$ All commendably evidence-based, so again, why has there been so little, if any, tangible benefit, particularly with respect to lost productivity?

\section{Have they been told?}

While the orthodox medical profession in general may have noted the evidence, the uninformed lay public remains largely unaware of this calamitous health care experience and paradigm shift. Or what they have been told is inconsistent with their clinical experience. ${ }^{10,11,13}$ Large-scale public education programs, while evidently of some limited benefit, are difficult to organize and can be very expensive., ${ }^{3,22}$ Nor is it clear regarding the extent and how lasting any effect of such programs might be. ${ }^{4}$ Although people harbor their own intrinsic fear of invasive treatment, the broader lay public has no convincing reason to abandon the SAB basis for low back pain. ${ }^{23,24}$ With what exactly are they to replace this deeply ingrained consequence of a concerted 20th century public relations program, the lay information service, and personal experience/observation? ${ }^{13,24-26}$ Especially when it is still being regularly reinforced by clinical encounters with a range of hands-on SAB-focused health care providers, who display utter confidence in their method and whose services afford relief from pain.

Although it has long been clear that any positive clinical results for hands-on treatments are for diagnostic and therapeutic reasons other than those originally thought, the lay public has little specific knowledge of or difficulty in accepting this fact, ${ }^{27-29}$ as outlined by Hartman. ${ }^{30}$ The powerful influence that provider beliefs and behaviors have on those of their patients is well recognized, and patient beliefs and behaviors have a direct effect on outcomes. ${ }^{27}$

It is unclear as to what influence large-scale public education programs might have had on choice of provider for low back pain. It is significant that the analysis by Dagenais et $\mathrm{al}^{2}$ found the largest mean cost (17\%) for low back pain to be 
for physiotherapy. This was equaled only by hospital inpatient services, both trailed by pharmacy and primary medical care at $13 \%$. In the US, an earlier estimate of all back pain patients who consult a chiropractor was $13 \% .{ }^{31}$ The study by Dagenais et $\mathrm{al}^{2}$ estimated that the mean proportion of patients under the care of a medical physician for low back pain was $20 \%$ compared with $30 \%$ for nonphysicians (physiotherapy, chiropractic and osteopathy, mental health). Evidence such as this indicates that, if the intent to reduce costs is serious, evidence-based professional education must involve not just orthodox clinicians but also alternative providers, specifically dispensers of hands-on therapy.

\section{Hands-on providers}

"Hands-on" refers to the philosophy and practice of providers whose stock-in-trade is the manual delivery of passive movement to, in this case, the spinal column and its associated structures. ${ }^{10}$ Hands-on therapy is of course a powerful clinical modality, albeit a nonspecific one. ${ }^{30}$ What, if any, might be its specific effect(s)?

Research confirms that passive therapeutic movement has no lasting effect on tissue length, position, shape, or content. ${ }^{28}$ A reassuring (to both practitioner and patient) "click" notwithstanding, pain reduction with thrust or oscillatory passive movement would appear to be mainly for neurological rather than for mechanical reasons..$^{28,32}$ Does the lay public fully appreciate the fact that, for instance, while some $90 \%$ of patients with symptoms of low back pain show radiographic evidence of disc pathology, so do $30 \%-50 \%$ of asymptomatic individuals $?^{33,34}$ What needs to be emphasized is that even if this were the source of their symptoms, it is not alterable in any therapeutically worthwhile way by hands-on or other noninvasive SAB-based treatment (eg, mechanical traction). ${ }^{35}$ All stakeholders need to bear in mind that Cochrane review evidence (admittedly less than ideal) currently shows that spinal manipulative therapy is of no or limited benefit for either acute or chronic low back pain. ${ }^{36-38}$

The current evidence suggests that psychophysically perceived movement impediments are not uniquely significant and, indeed, may often be artefactual. ${ }^{39}$ It is also worth pointing out that, in more than 100 years, there has been no demonstrable evidence of anything resembling a spinal joint subluxation. ${ }^{13,39}$ And, even if such a displacement or mechanical impediment to passive movement were shown to be present, what would be its clinical significance? It has always been difficult to accept that some minor, albeit palpable, abnormality of movement (position?) of the spinal joints could have a serious pathological effect on the visceral system, ${ }^{40,41}$ or that such an abnormality could be critically implicated in the cause of or recovery from chronic disabling low back pain. ${ }^{13}$

Nevertheless, as acknowledged, "something" can often be felt by clinicians as being different from the opposite side as the "norm". This diagnostic hands-on perception has misled dedicated professionals, and hence the gullible lay public, for decades. ${ }^{13,25,42}$ Simplistic idiosyncratic arcane philosophies with complex therapeutic rituals evolved ${ }^{43-47}$ based around this feeling and the fact that when manually perturbed (by hands-on therapy), both the mechanical "flaw" and the patients' symptoms frequently improve.

Thus, it is apparent that, in the absence of science, professional endorsement has come largely from a complex and notoriously unreliable source, ie, patient-reported improvement and provider enthusiasm. Possible reasons why ineffective treatments seem to work have recently been discussed by Hartman. ${ }^{30}$ Nonspecific factors that may positively influence patient responses to any treatment are well known, ${ }^{48,49}$ and hands-on therapy is recognized as having substantial nonspecific powers. ${ }^{30,50}$ These will not be discussed, other than to say that they are likely to be significant with treatments that are readily acceptable to the nonmedical person, especially if heavily sold to them. .,13,25,51,52 $^{2}$

\section{"What does manipulation do?" revisited}

There is now convincing evidence for the long-proposed activation of inbuilt inhibitory pain system(s), and as a result pain relief using oscillatory passive movement/ mobilization. $^{28,53,54}$

Mechanisms-based investigations into the activation of endogenous pain inhibitory systems with oscillatory passive movement and/or mechanical stimulation started in the 1980s. ${ }^{55}$ Since then, numerous studies have been conducted involving animals, patients, asymptomatic subjects, a variety of musculoskeletal pain conditions, and several different outcome variables, ${ }^{56-60}$ as reviewed by Bialosky et al. ${ }^{28}$ These studies have identified central nervous system pathways that are engaged along with likely inhibitory neurotransmitters and their receptors. Further inhibitory models that appear consistent with an empirically determined clinical process and its known consequences have yet to be investigated. ${ }^{61}$

Far from being disappointing, the known mechanicalstimulus pain inhibitory mechanism, and perhaps other physiological effects of passive movement, should be endorsed as good news for a hopefully better informed 
lay public. In this regard, it is tempting to propose that controlled passive oscillatory movement could have some therapeutic effect on the fluid environment of pathological tissue. That is, because it has long been suggested for some forms of massage, ${ }^{62}$ expertly selected and delivered passive movement helps to facilitate the passage of hypoxic blood/ plasma and lymph, along with its chemical pain-producing metabolites in the localized environment. ${ }^{63}$ Also yet to be researched is the proposal that graduated mechanical oscillatory perturbation of damaged tissue may have some direct beneficial influence on tissue repair. ${ }^{64}$ Along with psychophysical perceptions of passive movement impediment ("stiffness"), these are all areas that are in urgent need of investigation.

In any event, patients should be encouraged to welcome the fact that their nonspecific pain problem is not SAB-based. If this were the case, the pain would not be modifiable in any clinically relevant way using existing hands-on treatment, and patients generally do not relish the idea of invasive procedures. Beginning with the hands-on provider, this point needs to be driven home by any means available in educational programs funded by the public or otherwise in the future. ${ }^{65,66}$ The provider is also obliged to be familiar with and pass on to patients in lay language terms likely mechanisms for the ("non-red flag") low back pain their treatment is endeavouring to inhibit.

\section{“Non-red flag" back pain}

What might be the mechanism(s) for episodes of the very real "non-red flag" low back pain, which is often severe but generally self-limiting, that most of us have felt at some time? Well, to begin with, it should be pointed out that mechanical pain does not exist as a discrete clinical entity, ${ }^{67}$ and that there is only mechanically evoked or exacerbated pain. All clinically relevant pain is specific in that, at least initially, it has a biochemical basis.

Acute strain would result in initial short-lived protective nociception, but with sufficient soft tissue damage this is followed by chemically mediated inflammatory pain which is likely to increase in intensity, with symptoms of aching and throbbing over the next $12-24$ hours. ${ }^{68}$ During this time, naturally high-threshold peripheral nociceptive terminals sensitize to low intensity external mechanical and thermal stimuli, ie, gravity, posture, movement, and ambient temperature. This is enhanced by raised local temperature, pulsating blood vessels, lowered $\mathrm{pH}$, and additional chemicals being released internally. ${ }^{69}$ It may be difficult to identify precisely where this occurs acutely with low back pain and which innervated peripheral tissues are implicated in any specific episode. This would be influenced by force-related variables and could involve any or many of these variables. Particular symptom patterns, tissue imaging, and sensory blockade tests have been reported to help in the identification of such variables. ${ }^{70}$

Next is the issue of clinically relevant nontraumatic and "non-red flag" low back pain, as opposed to the aching brought on by routine physical activity which is mostly resolved by the following day. This pain does not include a history of acute strain or tissue damage, but instead manifests as a result of everyday stimulation and more or less spontaneously. ${ }^{71}$ The main culprit would appear to be periodic "leak" of material from the nucleus pulposus for various reasons, along with leak of pain-inducing chemicals into innervated areas of the intrinsically vulnerable human intervertebral disc. ${ }^{72,73}$ At some further point, continuing internal disc deterioration, vertebral end plate rupture, and vascular ingrowth provide a further additional chemical pathway for the onset of episodes of pain. ${ }^{34}$ The current view is that, for some decades into life, the disc is the major culprit for episodes of low back pain (including certain "red flag" types). While still retaining its potential to produce pain, later on in life the disc becomes desiccated and stiffened, and can be less troublesome in this regard.

Deterioration caused by weight-bearing and everyday activity, ie, osteoarthritis of the facet joints, may result in these joints becoming a significant source of the chemically induced pain flareups characteristic of this disease. ${ }^{74,75}$ Either source can be temporarily quite disabling, but most episodes generally have a good prognosis when managed with limited rest, analgesic and/or anti-inflammatory medication, physiotherapy assistance, "getting moving" where necessary, and graduated resumption of everyday activities despite minor pain. All of this is predicated by evidence-based information and explanation.

Could sustained/repeated "abnormal" posture and/or movement aggravate or initiate the situation? Certainly. While it is now acknowledged that far too much importance had been attributed to $\mathrm{SAB}$ factors in the past, ${ }^{76,77}$ as $\mathrm{McGill}^{76}$ points out, flawed movements can create symptom-aggravating "stress concentrations" (sic). It is necessary to emphasize that the important place of biomechanics in aggravation of low back pain cannot be dismissed. With gradual onset of osteoarthritis of the lumbar facet joints, pain evoked or enhanced by posture/ movement probably involves a buildup of pain chemicals, as well as hypoxia and lowering of the intra-articular $\mathrm{pH} .{ }^{74,75}$ There may be temporal summation of sensory input at the 
spinal cord level involving not only neurones but also glial cells (mainly astrocytes in cases of inflammatory pain, but perhaps microglia as well) that is passed on to the brain. ${ }^{78}$ Expert assessment and active reduction of posture/movement "stress pockets" could have duel therapeutic neurological consequences. One is removal of the mechanical stimulus adding to the chemically mediated pain, and another is alteration of the pattern of pain and pain-related afferent sensory input to supraspinal centers. The latter is proposed to be implicated in associative learning and memory for chronic low back pain along with its extinction. ${ }^{79-81}$

\section{What to do?}

Patients with non-red flag symptoms are in pain, want a diagnosis, and want the appropriate pain-relieving (curative?) treatment. What they need of course is an informed explanation for their symptoms. Ideally, they should also receive an informed realistic explanation as to what they are likely to experience over time. They need to know that, while there may well be other reasons, there is no $\mathrm{SAB}$ basis for them to expect otherwise. Above all, if the hands-on approach is to be used (and this can be a valuable precursor to their "getting moving") they need to be given an evidence-based explanation as to its therapeutic mechanism.

In every conceivable way, the inadequate diagnosis of nonspecific pain and its implications, including reassurance, means nothing to patients, and indeed could potentially be harmful without validation. ${ }^{82}$ The patients are quite correct in wanting a biological explanation for their pain. The pain is real, in that patients can feel it, despite what often cannot be found. ${ }^{83}$ It is reasonable to expect that appropriately managed pain, will steadily decrease in most instances. However, should it linger for pathological and/or premorbid psychosocial reasons, it is incumbent on the clinician to provide a reasonable explanation along with appropriate and multidisciplinary management where possible. Failure to do so may lead patients to one or both of two conclusions, ie, that the practitioner is incompetent (try elsewhere) or that they may be harboring some hidden sinister pathology that requires urgent investigation. Increasing disappointment with regard to both these generally incorrect premises can lead to mounting anxiety, anger, a sense of hopelessness and helplessness, and depression, leading to the onset or gross magnification of seriously complicating and chronicityinducing "yellow flags". ${ }^{84}$ These include increasing fear, catastrophizing, hypervigilance, and, above all, an irrational retreat from physical activity. ${ }^{85-87}$ This process shatters what otherwise might have been a good prognosis, compounds management difficulties, increases disability, and delays or prevents recovery, with costly loss of productivity. ${ }^{82,88,89}$

\section{Conclusion}

Given the advances in our understanding of low back pain that began back in the 1980s, failure to observe any worthwhile decrease in the figures for non-red flag low back pain is of considerable concern. While the direct (medical) costs of low back pain seem somewhat excessive, the major issue here is the enormous cost to society and individuals arising from loss of productivity. This includes absenteeism (sick leave, time off work), decreased productivity while at work (presenteeism), cost to the employer of hiring a replacement, compensation (claims paid), loss of earnings, utilization of public health services, litigation, and early retirement on a disability pension. ${ }^{2}$

It is proposed that a major reason for prolonged time away from fully productive work/home duties is that patients with or without significant pain believe or suspect that they harbor a structural defect of the spinal column that carries inherent danger. ${ }^{90,91}$ Herein lies the basis for irrational withdrawal from all but essential everyday physical activity and its costly consequences. ${ }^{24,25,88,92-98}$ Inadvertently or otherwise, the belief and its consequences continue to be reinforced on a daily basis, particularly by hands-on providers of care. ${ }^{25}$

If, as is claimed, large-scale, expensive education programs purport to target widely held misconceptions about back pain, ${ }^{4,22}$ they are not sufficiently explicit. Probably one of the most widely held beliefs, and a disabling one for the lay public, is that back pain is a sign that some spinal structure has become abnormally positioned, ${ }^{25}$ and that unless corrected, the spinal column will become biomechanically unsound and unable to withstand everyday forces. Symptoms are attributed to the resulting abnormal distribution of physical stresses (ie, mechanical pain due to "displaced" joints and muscles), but can also be potentially destructive in origin (eg, a "pinched" nerve), all of which may be tinged with the nagging fear of latent danger, ie, compromise of the spinal cord. ${ }^{99}$

The critical issue with this belief is its corollary, ie, that it is possible for the symptomatic "out of place" structure to be restored to its original position by noninvasive hands-on therapy, ${ }^{13,25}$ that pain will steadily decrease, and everyday activities may be safely resumed. The latter turns out to be "best practice", although for quite the wrong reasons. However, a word of caution: all upright humans harbor this intrinsic structural weakness, and the problem can recur. What initially enthusiastic insurers (and other payers) did not allow for was the lifetime of adjustment and other position-related 
treatments for the all too regularly backsliding structural flaw, and with this, continuous reinforcement of the erroneous belief. It is important to note that these (mainly thrust) maneuvers are used virtually routinely by at least some providers despite recent unfavorable research demonstrating their lack of clinical specificity and efficacy, as mentioned earlier. This has led to the search for so-called clinical prediction rules, ie, the best (contra)indicators. Unfortunately, an up-to-date review found that the current evidence for hands-on therapy in patients with low back pain "... does not enable confident direct clinical application of any of the identified clinical prediction rules". ${ }^{100}$ Clearly, there is a need for further methodologically rigorous research.

If the assumed significant cost benefits of evidence-based public education programs along with clinical best practice by orthodox medical practitioners are to have any chance of materializing, then these initiatives need to be supported by the clinical experience of patients. There is compelling evidence that this clinical experience is in fact undermined by what actually occurs in practice as a result of fear-avoidant provider attitudes and advice, along with SAB-based treatment. ${ }^{101}$ This issue has been discussed in detail by Darlow et al. ${ }^{27}$ Recent studies, such as that by Deakin and Richardson, ${ }^{102}$ highlight the situation with respect to management of low back pain by physiotherapists. In spite of their modern science-based biopsychosocial training, physiotherapists in this seminal study reasoned and practiced completely in accordance with SAB-based principles (commonly referred to as the biomedical model for low back pain), ${ }^{49,103}$ which is at best tacit or "sin of omission" belief reinforcement. Similarly revealing is a recent paper by Ebrall ${ }^{104}$ (himself from the camp of true believers) that criticizes colleagues who profess to reject the subluxation concept while at the same time continuing to imply its existence and significance with patients for financial gain.

There are probably several understandable reasons why clinicians do not always follow clinical best practice guidelines. ${ }^{4,105}$ With hands-on providers, it is simply because these guidelines are fundamentally incompatible with their professional raison d'être. ${ }^{12,13,25,39,40,42,44,106}$ How hands-on clinicians might go about conveying current evidence-based messages to their patients while retaining at least the core of their clinical methods is for them to decide. However, the time to decide has definitely arrived. An example of a simple narrative, based on what has been discussed, could go something like the following:

"Yes, my examination confirms that this particular area of your spine is not moving as it should. The reason it is prevented from doing so is the presence of pain - that is a part of pain's job, and we have already discussed the likely chemical basis for your pain."

"Because you are unable to move about normally, to get you started I am going to use my hands to help your back to move properly. We are greatly assisted in this regard by the fact that when skillfully applied the treatment I use directly inhibits pain."

"Pain inhibition is also useful when your own muscles begin to take over the work. As things improve you will no longer need it. Nevertheless, I will continue to serve as your active movement guide, and general adviser, for as long as is necessary."

\section{Disclosure}

The author reports no conflicts of interest in this work.

\section{References}

1. Waddell G. A new clinical model for the treatment of low back pain. Spine (Phila Pa 1976). 1987;12:632-644.

2. Dagenais S, Caro J, Haldeman S. A systematic review of low back pain cost of illness studies in the United States and internationally. Spine J. 2008;8:8-20.

3. Buchbinder R, Gross DP, Werner EL, Hayden JA. Understanding the characteristics of effective mass media campaigns for back pain and methodological challenges in evaluating their effects. Spine (Phila Pa 1976). 2008;33:74-80.

4. Gross DP, Deshpande S, Werner EL, Reneman MF, Miciak MA, Buchbinder R. Fostering change in back pain beliefs and behaviors: when public education is not enough. Spine J. 2012;12:979-988.

5. Linton SJ, Maher CG, Van Zundert J. Low back pain: basic mechanisms, treatment, and management. In: Tracey I, editor. Pain 2012 Refresher Courses 14th World Congress on Pain. Seattle, WA: IASP Press; 2012.

6. Druss BG, Marcus SC, Olfson M, Pincus HA. The most expensive medical conditions in America. Health Aff (Millwood). 2002;21:105-111.

7. Luo X, Pietrobon R, Sun SX, Liu GG, Hey L. Estimates and patterns of direct health care expenditure among individuals with back pain in the United States. Spine (Phila Pa 1976). 2004;29:79-86.

8. Stewart WF, Ricci JA, Chee E, Morganstein D, Lipton R. Lost productive time and cost due to common pain conditions in the US workforce. JAMA. 2003;290:2443-2454.

9. Fordyce WE, editor. Back Pain in the Workplace. Seattle, WA: IASP Press; 1995.

10. Harvey E, Burton AK, Moffett JK, Breen A; UK BEAM Trial Team. Spinal manipulation for low-back pain: a treatment package agreed by the UK chiropractic, osteopathy and physiotherapy professional associations. Man Ther. 2003;8:46-51.

11. Reme SE, Hagen EM, Eriksen HR. Expectations, perceptions, and physiotherapy predict prolonged sick leave in subacute low back pain. BMC Musculoskelet Disord. 2009;13(10):139.

12. Cramer G, Budgell, B, Henderson C, Khaksa P, Pickar J. Basic science research related to chiropractic spinal adjusting: the state of the art and recommendations revisited. J Manipulative Physiol Ther. 2006;29:726-761.

13. Ernst E. Chiropractic: a critical evaluation. J Pain Symptom Manage. 2008;35:544-562.

14. Kaltenborn FM. The Spine: Basic Evaluation and Mobilization Techniques. Oslo, Norway: Olaf Norlis Bokhandel; 1989. 
15. Maitland GD. Vertebral Manipulation, 5th ed. London, UK: Butterworths; 1986.

16. Chan CW, Peng P. Failed back pain surgery syndrome. Pain Med. 2011;12:577-606.

17. Woolf CJ. Recent advances in the pathophysiology of acute pain. $\mathrm{Br} J$ Anaesth. 1989;63:139-146.

18. Waddell G. Biopsychosocial analysis of low back pain. Ballieres Clin Rheumatol. 1992;6:523-557.

19. Turk DC, Swanson KS, Tunks ER. Psychological approaches in the treatment of chronic pain patients - when pills, scalpels, and needles are not enough. Can J Psychiatry. 2008;53:213-223.

20. Koes BW, van Tulder M, Macedo LG, McAuley J, Maher C. An updated review of clinical guidelines for the management of non-specific low back pain in primary care. Eur Spine J. 2010;19:2075-2094.

21. Frost H, Lamb SE, Doll HA, Carver P, Stewart-Brown S. Randomised controlled trial of physiotherapy compared with advice for low back pain. BMJ. 2004;329:708.

22. Buchbinder R, Jolley D, Wyatt M. Population based intervention to change back pain beliefs and disability: three part evaluation. $B M J$. 2001;322:1516-1520.

23. Klaber Moffett J, Newbronner E, Waddell G, Croucher K, Spear S. Public perceptions about low back pain and its management: a gap between expectations and reality? Health Expect. 2000;3:161-168.

24. Gross DP, Ferrari R, Russell AS, et al. A population-based survey of back pain beliefs in Canada. Spine (Phila Pa 1976). 2006;31:2142-2145.

25. Zusman M. Spinal pain patients' beliefs about pain and physiotherapy. Aust J Physiother. 1984;30:145-151.

26. Zusman M. Instigators of activity intolerance. Man Ther. 1997;2: 75-86.

27. Darlow B, Fullen BM, Dean S, Hurley DA, Baxter GD, Dowell A. The association between health care professional attitudes and beliefs and the attitudes and beliefs, clinical management, and outcomes of patients with low back pain: a systematic review. Eur J Pain. 2012;16:3-17.

28. Bialosky JE, Bishop MD, Price DD, Robinson ME, George SZ. The mechanisms of manual therapy in the treatment of musculoskeletal pain: a comprehensive model. Man Ther. 2009;14:531-538.

29. Zusman M. The modernisation of manipulative therapy. Int J Clin Med. 2011;2:644-649.

30. Hartman SE. Why do ineffective treatments seem helpful? A brief review. Chiropractic and Osteopathy; 2009. Available from: http:/ www.chiroandosteo.com/content/17/1/10. Accessed March 18, 2013.

31. Carey TS, Evans AT, Hadler NM, et al. Acute severe low back pain. A population based study of prevalence and care seeking. Spine (Phila Pa 1976). 1996;21:339-344.

32. Zusman M. Mechanisms of musculoskeletal physiotherapy. Phys Ther Rev. 2004;9:39-49.

33. Liebenson C. Musculoskeletal myths. J Bodyw Mov Ther. 2012;16: $165-182$.

34. Raj PP. Intervertebral disc: anatomy-physiology-pathophysiologytreatment. Pain Pract. 2008;8:18-44.

35. Macario A, Pergolizzi JV. Systematic literature review of spinal decompression via motorized traction for chronic discogenic low back pain. Pain Pract. 2006;6:171-178.

36. Rubinstein SM, Terwee CB, Assendelft WJJ, de Boer MR, van Tulder MW. Spinal manipulative therapy for acute low-back pain. Available from: http://summaries.cochrane.org/CD008880/spinal-manipulativetherapy-for-acute-low-back-pain. Accessed April 3, 2011.

37. Rubinstein SM, van Middelkoop M, Assendelft WJJ, de Boer MR, van Tulder MW. Spinal manipulative therapy for chronic low-back pain. Cochrane Database Syst Rev. 2011;2:CD008112.

38. Posadski P. Is spinal manipulation effective for pain? An overview of systematic reviews. Pain Med. 2012;13:754-761.

39. Homola S. Real orthopaedic subluxations versus imaginary chiropractic subluxations. Focus Altern Complement Ther. 2010;15:284-287.

40. Henderson CNR. The basis for spinal manipulation: chiropractic perspective of indications and theory. J Electromyogr Kinesiol. 2012;22:632-642.
41. Bialosky JE, Simon CB, Bishop MD, George SZ. Basis for spinal manipulative therapy: a physical therapist perspective. J Electromyogr Kinesiol. 2012;22:643-647.

42. Troyanovich SJ, Harrison DD. Motion palpation: its time to accept the evidence. J Manipulative Physiol Ther. 1998;21:568-571.

43. Harmonet C. Andrew Taylor Still and the birth of osteopathy (Baldwin, Kansas, USA, 1855). Joint Bone Spine. 2003;70:80-84.

44. Homola S. Inside Chiropractic. New York, NY: Prometheus; 1999.

45. Maitland GD. Vertebral Manipulation, 1st ed. London, UK: Butterworths; 1964.

46. Kaltenborn FM. Mobilisation of the Spinal Column. Wellington, New Zealand: New Zealand University Press; 1970.

47. Edwards BC. Manual of Combined Movements, 1st ed. Oxford, UK: Butterworths-Heinemann; 1992.

48. Koshi EB, Short CA. Placebo theory and its implications for research and clinical practice. Pain Pract. 2007;7:4-20.

49. Enck P, Benedetti F, Schedlowski M. New insights into the placebo and nocebo responses. Neuron. 2008;59:195-206.

50. Shapiro AK, Shapiro E. The Powerful Placebo: From Ancient Priest to Modern Physician. Baltimore, MD: Johns Hopkins University Press; 1997.

51. Baer HA. Practice-building seminars in chiropractic: a petit bourgeois response to biomedical domination. Med Anthropol Q. 1996;10:29-44.

52. Novella S. The golden age of quackery and anti-science. The Scientific Review of Alternative Medicine. 2007;11:6-8.

53. Wyke B, Polacek P. Articular neurology: the present position. J Bone Joint Surg. 1975;57B:401.

54. Zusman M. What does manipulation do? The need for basic research. In: Boyling JD, Palastanga N, Jull GA, Lee DG, Grieve GP, editors. Grieve's Modern Manual Therapy. Edinburgh, Scotland: Churchill Livingstone; 1994.

55. Zusman M, Edwards BC, Donaghy A. Investigation of a proposed mechanism for the relief of spinal pain with passive joint movement. Journal of Manual Medicine. 1989;4:58-61.

56. Moss P, Sluka K, Wright A. The initial effects of knee joint mobilisations on osteoarthritic hyperalgesia. Man Ther. 2007;12: 109-118.

57. Skyba DA, Radharkrishnan R, Rohlwing JJ, Wright A, Sluka KA. Joint manipulation reduces hyperalgesia by activation of monoamine receptors but not opioid or GABA receptors in the spinal cord. Pain. 2003;106:159-168.

58. Vicenzino B, Collins D, Wright A. The initial effects of a spinal manipulative physiotherapy treatment to the pain and dysfunction of lateral epicondylalgia. Pain. 1996;68:69-74.

59. Sterling M, Jull G, Wright A. Cervical mobilisation: concurrent effects on pain, sympathetic nervous system activity and motor activity. Man Ther. 2002;6:72-81.

60. Vicenzino B, Wright A. Physical treatments. In: Strong J, Unruh A, Wright A, Baxter GD, editors. Pain: A Textbook for Physiotherapists. Edinburgh, Scotland: Churchill Livingstone; 2002.

61. Zusman M. Mechanism of mobilization. Phys Ther Rev. 2011;16:233-236.

62. Weerapong P, Hume PA, Kolt GS. The mechanisms of massage and effects on performance, muscle recovery and injury prevention. Sports Med. 2005;35:235-256.

63. Schmid A. Implications of mild peripheral nerve compression beyond the lesion site. Mechanisms and interventions. PhD thesis. Queensland, Australia: Department of Health and Rehabilitation Sciences, The University of Queensland; 2011.

64. Zusman M. There's something about passive movement ... . Med Hypotheses. 2010;75:106-111.

65. Evans DW, Breen AC, Pincus T, et al. The effectiveness of a posted information package on the beliefs and behavior of musculoskeletal practitioners. The UK chiropractors, osteopaths and musculoskeletal physiotherapists low back pain managemENT (COMPLeMENT) randomized trial. Spine (Phila Pa 1976). 2010;35:858-866.

66. Werner EL, Gross DP, Atelie S, Ihlebraek C. Healthcare provider beliefs unaffected by a media campaign. Scand J Prim Health Care. 2008;26:50-56. 
67. Wyke B. The neurology of joints: a review of general principles. Clin Rheum Dis. 1981;7:223-239.

68. Wood JN. Molecular mechanisms of nociception and pain. In: Cervero F, Jensen TS, editors. Handbook of Clinical Neurology. Pain. 2006;81:49-59.

69. Johanek L, Shim B, Meyer RA. Primary hyperalgesia and nociceptor sensitization. In: Cervero F, Jensen TS, editors. Handbook of Clinical Neurology. Pain. 2006;81:35-47.

70. Artner J, Kurz S, Cakir B, Reichel H, Lattig F. Does diagnosis influence the outcome in a multimodal outpatient pain management program for low back pain and sciatica? A comparative study. J Multidiscip Healthc. 2012;5:163-167.

71. Carragee E, Alamin T, Cheng I, Franklin T. Does minor trauma cause serious low back illness? Spine (Phila Pa 1976). 2006;31:2942-2949.

72. Kallewaard JW, Terheggen MA, Groen GJ, et al. Discogenic low back pain. Pain Pract. 2010;10:560-579.

73. Burke JG, Watson WG, McCormack D, et al. Intervertebral discs which cause low back pain secrete high levels of proinflammatory mediators. J Bone Joint Surg Br. 2002;84B:196-201.

74. Igarashi A, Kikuchi Konno S. Correlation between inflammatory cytokines released from the lumbar facet joint tissue and symptoms in degenerative lumbar spinal disorders. J Orthop Sci. 2007;12:154-160.

75. Mease PJ, Hanna S, Frakes EP, Altman RD. Pain mechanisms in osteoarthritis: understanding the role of central pain and current approaches to its treatment. $J$ Rheumatol. 2011;38:1546-1551.

76. McGill S. Invited response. J Bodyw Mov Ther. 2011;15:150-152.

77. Fryer G. Invited response. J Bodyw Mov Ther. 2011;15:138-140.

78. Ikeda H, Kiritishi T, Murase K. Contribution of microglia and astrocytes to the central sensitization, inflammatory and neuropathic pain in the juvenile rat. Mol Pain. 2012;8:43.

79. Zusman M. Associative memory for movement-evoked chronic back pain and its extinction with musculoskeletal physiotherapy. Phys Ther Rev. 2008;13:57-68.

80. De Peuter S, Van Diest I, Vansteenwegen D, Van den Bergh, Vlaeyen JWS. Understanding fear of pain in chronic pain: interoceptive fear conditioning as a novel approach. Eur J Pain. 2011;15:889-894.

81. Meulders A, Vansteenwegen D, Vlaeyen JWS. The acquisition of fear of movement-related pain and associative learning: a novel pain-relevant human fear conditioning paradigm. Pain. 2011;152:2460-2469.

82. Linton SJ, BoersmaK, Vangronsveld K, Fruzzetti A. Painfully reassuring? The effects of validation on emotions and adherence in a pain test. Eur J Pain. 2012;16:592-599.

83. Loeser JD. Chronic pain is more than just a peripheral event. $J$ Pain. 2012;13:930-931.

84. Kendall NAS, Linton SJ, Main CJ. Guide to Assessing Psychosocial Yellow Flags in Acute Low Back Pain Risk Factors for Long Term Disability and Work Loss. Wellington, New Zealand: Accident Rehabilitation and Compensation Insurance Corporation of New Zealand and the National Health Committee; 1997.

85. Crombez G, van Damme S, Eccleston C. Hypervigilance to pain: an experimental and clinical analysis. Pain. 2005;116:4-7.

86. Linton SJ, Nicholas MK, McDonald S, et al. The role of depression and catastrophysing in musculoskeletal pain. Eur J Pain. 2011;15: 416-422.

87. Vlaeyen JWS, Kole-Snijders AMJ, Boeren RGB, van Eek H. Fear of movement/(re)injury in chronic low back pain and its relation to behavioral performance. Pain. 1995;62:363-372.

Journal of Multidisciplinary Healthcare

\section{Publish your work in this journal}

The Journal of Multidisciplinary Healthcare is an international, peerreviewed open-access journal that aims to represent and publish research in healthcare areas delivered by practitioners of different disciplines. This includes studies and reviews conducted by multidisciplinary teams as well as research which evaluates the results or conduct of such teams or Submit your manuscript here: http://www.dovepress.com/journal-of-multidisciplinary-healthcare-journal
88. Main CJ, Foster NE, Buchbinder R. How important are back pain beliefs and expectations for satisfactory recovery from back pain? Best Pract Res Clin Rheumatol. 2010;24:205-217.

89. Pincus T, Vogel S, Burton AK, Santos R, Field AP. Fear avoidance and prognosis in back pain: a systematic review and synthesis of current evidence. Arthritis Rheum. 2006;54:3999-4010.

90. Gheldof EL, Crombez G, Van den Brussche E, et al. Pain related fear predicts disability, but not pain severity: a pathway analytic approach of the fear avoidance model. Eur J Pain. 2010;14:870. e1-e9.

91. Swinkels-Meewisse IE, Roelofs J, Schouten EG, Verbeek AL, Oostendorp RA, Vlaeyen JW. Fear of movement/(re)injury predicting chronic disabling low back pain: a prospective inception cohort study. Spine (Phila Pa 1976). 2006;31:658-664.

92. Du Bois M, Szpalski M, Donceel P. Patients at risk for long-term sick leave because of low back pain. Spine J. 2009;9:350-359.

93. Geisser ME, Haig AJ, Theisen ME. Activity avoidance and function in persons with chronic back pain. J Occup Rehabil. 2000;10:215-227.

94. Leeuw M, Goossens ME, Linton SJ, Crombez G, Boersma K, Vlaeyen JW. The fear avoidance model of musculoskeletal pain: current state of scientific evidence. J Behav Med. 2007;30:77-94.

95. Raymond A, Bouton C, Richard I, et al. Psychosocial risk factors for chronic low back pain in primary care - a systematic review. Fam Pract. 2011;28:12-21.

96. Werner EL, Hileback C, Skouen JS, Lacrum E. Beliefs about low back pain in the Norwegian general population: are they related to pain experiences and health professionals? Spine (Phila Pa 1976). 2005;30:1770-1776.

97. Zusman M. Structure-oriented beliefs and disability due to back pain. Aust J Physiother. 1998;44:13-20.

98. Ihlebaek C, Eriksen HR. The "myths" of low back pain: status quo in Norwegian general practitioners and physiotherapists. Spine (Phila Pa 1976). 2004;16:1818-1822.

99. Mixter WJ, Barr JS. Rupture of the intervertebral disc with involvement of the spinal canal. N Engl J Med. 1934;21:201-214.

100. Haskins R, Rivett DA, Osmotherly PG. Clinical prediction rules in the physiotherapy management of low back pain: a systematic review. Man Ther. 2012;17:9-21.

101. Houben RM, Ostelo RW, Vlaeyen JW, Wolters PM, Peters M, Stomp-van den Berg SG. Health care providers' orientations towards common low back pain predict perceived harmfulness of physical activities and recommendations regarding return to normal activities. Eur J Pain. 2005;9:173-183.

102. Deakin AR, Richardson B. Physiotherapists pain beliefs and their influence on the management of patients with chronic low back pain. Spine (Phila Pa 1976). 2004;29:783-795.

103. Jeffrey JE, Foster NE. A qualitative investigation of physical therapists' experiences and feelings of managing patients with nonspecific low back pain. Phys Ther. 2012;92:266-278.

104. Ebrall P. Commentary: subluxation, what's in a name? Chiropractic Journal of Australia. 2011;41:110-112.

105. Cabana MD, Rand CS, Powe NR, et al. Why don't clinicians follow clinical practice guidelines? A framework for improvement. JAMA. 1999;282:1458-1465.

106. Ernst E, Gilbey A. Chiropractic claims in the English-speaking world. N Z Med J. 2010;123:36-44.

healthcare processes in general. The journal covers a wide range of areas and welcomes submission from practitioners at all levels, from all over the world. The manuscript management system is completely online and includes a very quick and fair peer-review system. Visit http://www.dovepress.com/testimonials.php to read real quotes from published authors. 